\title{
As sucessões carbonáticas neoproterozóicas do Cráton do São Francisco e os depósitos de fosfato: correlações e fosfogênese
}

\author{
Andreia L. Sanches ${ }^{1,2}$, Aroldo Misi ${ }^{1}$, Alan J. Kaufman ${ }^{3}$ \& Karem Azmy ${ }^{4}$
}

\begin{abstract}
Resumo As sucessões sedimentares neoproterozóicas do Cráton do São Francisco são constituídas por espessas camadas carbonáticas e silicicásticas acumuladas em bacias marinhas epicontinentais e em bacias de margem passiva que bordejam a área cratônica. Pelo menos dois ciclos transgressivo-regressivos são reconhecidos durante a evolução das sucessões essencialmente carbonáticas. Essas sucessões, que formam os Grupos Vazante, Bambuí e Una, repousam sobre diamictitos glácio-marinhos de provável idade Sturtiana. Um outro horizonte de diamictitos glaciais, foi observado nas unidades de topo do Grupo Vazante. De um modo geral, as semelhanças entre as litofácies, assim como a presença de depósitos de fosfato e de sulfetos de $\mathrm{Zn}$ - $\mathrm{Pb}$ restritos a estreitos horizontes estratigráficos, sugerem que os Grupos Vazante, Bambuí e Una podem ser correlacionáveis. Os dados isotópicos de Sr obtidos a partir de amostras bem preservadas de carbonatos e de carbonatofluorapatita dessas seqüências, que variam entre 0,70763 e 0,70794 , confirmam as correlações e são indicativos de uma idade em torno de $650 \mathrm{Ma}$, embora razões obtidas anteriormente em duas amostras $(0,70614$ e 0,70684$)$ possam sugerir idades mais antigas. Dados de isótopos de carbono em carbonato-fluorapatita revelam fortes picos negativos, variando entre -3,47 e -12,25\% VPDB na área cratônica, e entre -1,3 e -9,61\% VPDB nos carbonato-fluorapatitas hospedados por carbonatos das bacias de margem passiva do Grupo Vazante, sugerindo que a concentração primária de $\mathrm{P}$ ocorreu em ambientes anóxicos, em ambos os contextos geotectônicos. Os carbonatos hospedeiros são moderadamente enriquecidos em ${ }^{13} \mathrm{C}$, com valores positivos de $\delta^{13} \mathrm{C}$ variando de $+2,0$ a $+9,6 \%$ VPDB nas diferentes seções. As concentrações primárias de fosfato ocorrem após sucessões glaciogênicas e sua origem pode estar relacionada à alta produtividade orgânica, como conseqüência dos eventos glaciais.
\end{abstract}

Palavras-chave: fosforito, Neoproterozóico, Cráton do São Francisco.

\begin{abstract}
Neoproterozoic Carbonate Sequences of the São Francisco Craton and the Phosphate Deposits: Correlation and Phosphogenesis. The neoproterozoic carbonate successions of the São Francisco craton are formed by thick carbonate and siliciclastic strata accumulated in epicontinental seaways, and on passive margins. At least two transgressive-regressive sea level cycles have been recognized during the evolution of the carbonate mega-sequences. These successions, represented by the Vazante, Bambuí, and Una Groups, lie above basal glacio-marine diamictites of probable Sturtian age, and an upper glacio-marine diamictite, was observed in upper units of the Vazante Group. The broad similarities of lithofacies, as well as the presence of phosphate and sulfide $(\mathrm{Zn}, \mathrm{Pb})$ deposits restricted to narrow stratigraphic intervals, suggest that the Vazante, Bambuí and Una Groups may be correlative. The Sr isotope data from well preserved carbonates and carbonate fluorapatite from each of these successions, ranging from 0.70763 to 0.70794 , support the general correlation and are indicative of seawater composition around $650 \mathrm{Ma}$, although the lower ${ }^{87} \mathrm{Sr} /{ }^{86} \mathrm{Sr}$ values of 0.70614 at the Vazante carbonates may suggest that this unit is older than the Bambuí and Una carbonate rocks. Carbon isotope data of carbonate fluorapatite reveal sharp negative excursions between -3.47 and $-12.25 \%$ VPDB in the cratonic area, and between -1.3 and $-9.61 \%$ VPDB in the carbonate fluorapatite hosted by the passive margin Vazante carbonates, suggesting that primary P concentration was accumulated in strong anoxic environments in both geotectonic settings. Carbonate hosting the phosphate deposits in these units are moderately enriched in ${ }^{13} \mathrm{C}$, ranging from positive $\delta^{13} \mathrm{C}$ values of +2.0 and $+9.6 \%$ VPDB in the different sections. Primary phosphate accumulations occur above glaciogenic successions. We suggest that these concentrations may be due to high organic productivity after glacial events.
\end{abstract}

Keywords: phosphorite, Neoproterozoic, São Francisco Craton.

1 - Grupo de Metalogênese, Centro de Pesquisa em Geofísica e Geologia, Instituto de Geociências, Universidade Federal da Bahia, Salvador(BA), Brasil. E-mail: misi@ufba.br

2 - Departamento de Ciências Naturais, Universidade Estadual do Sudoeste da Bahia (BA), Brasil. E-mail:alsanches@yahoo.com

3 - Department of Geology, University of Maryland, College Park, MD 20742, USA

4 - Department of Earth Sciences, Memorial University of Newfoundland, 300 Prince Philip Drive St. John's, NL, Canada A1B 3 X5. 
INTRODUÇÃO Os depósitos de fosforito que ocorrem nas bacias sedimentares neoproterozóicas do Cráton do São Francisco (Fig. 1) estão relacionados a um amplo episódio de fosfogênese ocorrido durante o final do Proterozóico. O estudo desses depósitos é de grande importância não apenas por causa de suas implicações econômicas, mas também considerando a possibilidade de interpretar os paleoambientes de sedimentação nas bacias por meio de medidas analíticas de diversas natu- rezas (incluindo isótopos de $\mathrm{C}, \mathrm{O}, \mathrm{S}, \mathrm{Sr}$, dentre outras) em amostras de carbonato-fluorapatita ou francolita, o principal mineral que compõe o fosforito marinho. Esse complexo sistema mineral que é o carbonato-fluorapatita geralmente preserva com bastante confiabilidade diversos tipos de assinaturas isotópicas que podem indicar as condições físico-químicas do ambiente em que se formaram e, consequentemente, podem também ser usadas para compreender a evolução das bacias sedi-

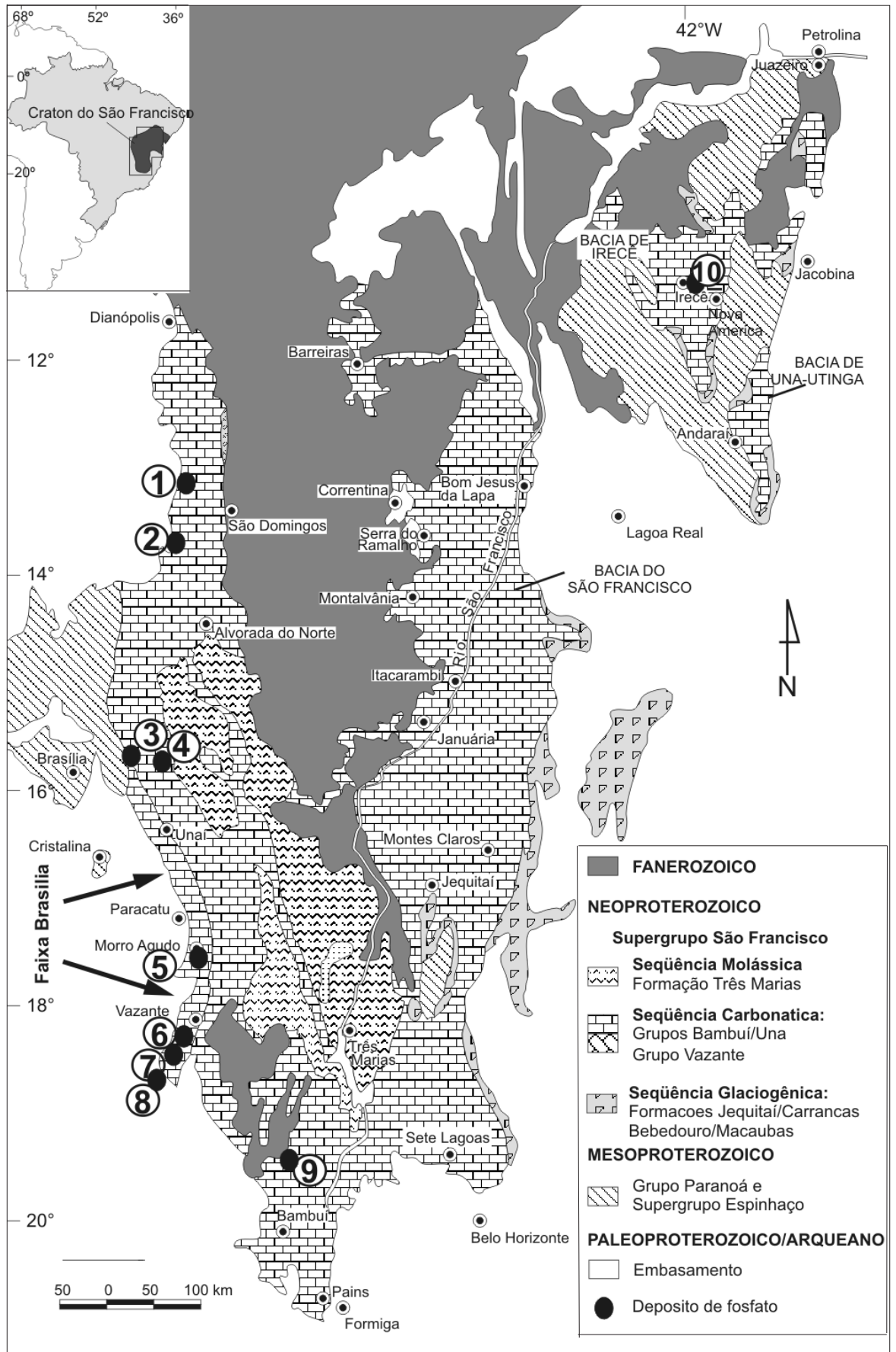

Figura 1 - Mapa geológico simplificado do Cráton do São Francisco com as bacias neoproterozóicas e os depósitos de fosfato. 1 Campos Belo e Monte Alegre 2 Nova Roma 3 Formosa 4 Cabeceiras 5 Morro Agudo 6 Lagamar 7 Rocinha 8 Coromandel 9 Cadro do Abaeté 8 Irecê e América Dourada. 
mentares hospedeiras e para o estabelecimento de correlações estratigráficas regionais ou mesmo globais.

Neste trabalho são apresentadas novas análises de $\delta^{18} \mathrm{O}, \delta^{13} \mathrm{Ce}^{87} \mathrm{Sr} /{ }^{86} \mathrm{Sr}$ de carbonato-fluorapatitas e das rochas encaixantes carbonáticas, à luz de dados previamente publicados (Misi et al. 2007, Misi \& Kyle 1994), procurando-se entender melhor a evolução das bacias e dos processos de fosfogênese relacionados. Os dados de isótopos de $\mathrm{Sr}$, assim como de carbono, tanto dos carbonatos quanto dos depósitos de fosfato dão suporte às correlações propostas.

\section{ARCABOUCO GEOTECTONNICO E CORRELA-}

ÇÕES O Cráton do São Francisco formou-se durante o Paleoproterozóico, a partir da aglutinação de vários blocos cratônicos de idade arqueana. Junto com suas bacias marginais e suas coberturas sedimentares, forma uma das mais importantes unidades geotectônicas da América do Sul, considerando os aspectos científicos e econômicos envolvidos.

As bacias sedimentares neoproterozóicas do Cráton do São Francisco evoluíram a partir de eventos extensionais ocorridos entre 900 e $600 \mathrm{Ma}$. (Condie 2002). As sucessões sedimentares depositadas durante esses eventos estão distribuídas nos seguintes ambientes geotectônicos:

A) Sucessões sedimentares carbonáticas e siliciclásticas depositadas em ambientes estáveis (cratônicos) representadas pelo Grupo Bambuí, na Bacia do São Francisco, pelo Grupo Una, nas bacias de Irecê e Una-Utinga, e pelo Grupo Rio Pardo, na Bacia do Rio Pardo.

B) Rochas carbonáticas e siliciclásticas, por vezes intensamente deformadas, em bacias de margem passiva, bordejando as áreas cratônicas (estáveis). Incluem os grupos Ibiá e Vazante (faixa de dobramentos Brasília), assim como os grupos Miaba, Canudos e Vasa Barris (faixa de dobramentos Sergipana) e o Grupo Macaúbas (faixa de dobramentos Araçuaí).

Três mega-seqüências estratigráficas estão representadas tanto nas zonas estáveis plataformais como nas bacias de margem passiva: Glaciogênicas, Carbonáticas e Molássicas, separadas por discordâncias de primeira ordem. Dentro de cada mega-seqüência existe também limites de outras ordens que são úteis para o estabelecimento de correlações regionais (Misi 2001). As mega-seqüências carbonáticas apresentam pelo menos dois ciclos transgressivo-regressivos (Fig. 2).

A estratigrafia das bacias neoproterozóicas revista neste trabalho leva em conta os trabalhos publicados por diversos pesquisadores (Kawashita 1998, Martins 1999, Dardenne 2000, 2001, Misi 2001 e referências, Misi et al. 2007).

Uma breve descrição das sucessões estratigráficas e da quimioestratigrafia dos Grupos Vazante, Bambuí e Una será apresentada, à luz de estudos anteriores realizados pelos autores e por outros pesquisadores, referidos ao longo do texto.

Grupo Vazante A litoestratigrafia e a quimioestra-

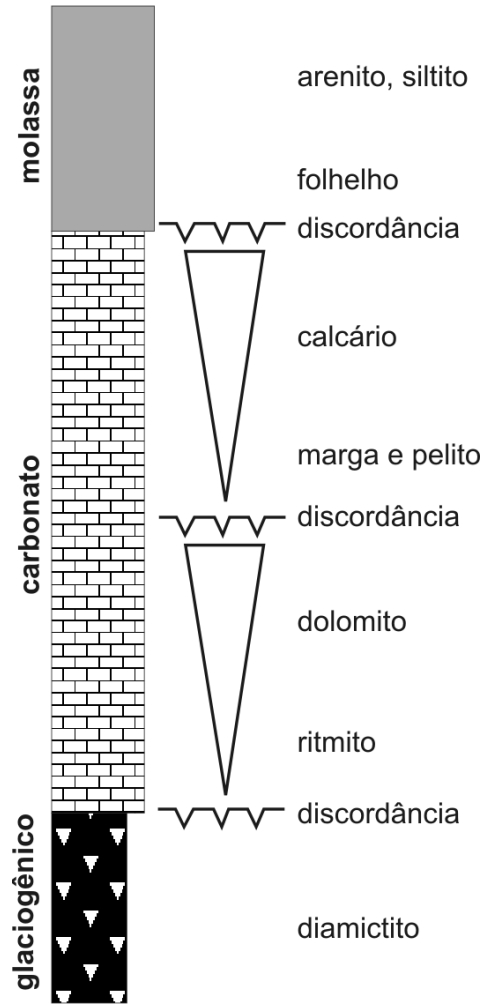

Figura 2 - Esquema geral da estratigrafia das sucessões neoproterozóicas do Cráton do São Francisco mostrando as três megasseqüencias e os dois subciclos da megasseqüencia carbonática, de acordo com Misi et al. (2007).

tigrafia do Grupo Vazante foram estudados com mais detalhe nesta década por Dardenne (2001), Azmy et al. (2001) e Azmy et al. (2005). Esse Grupo é formado por espessas sucessões carbonáticas $(>3000 \mathrm{~m})$, dominantemente dolomíticas, que repousam sobre diamictitos de provável origem glácio-marinha (D I). Observações recentes mostraram a existência de um segundo horizonte glácio-marinho (D II) no topo da seqüência (Fig. 3), caracterizado pela presença de diamictitos e dropstones intercalados em folhelhos orgânicos sob a Formação Lapa (Brody et al. 2004, Olcott et al. 2005, Azmy et al. 2005) (Fig. 4).

Os carbonatos do Grupo Vazante depositaramse em bacia de margem passiva e em plataforma marinha rasa, tendo sido completamente dolomitizados. A partir de uma detalhada amostragem de testemunhos de sondagem em furos realizados pela Votorantim Metais Zinco, Azmy et al. (2001) e Azmy et al. (2005) demonstraram que:

(1) A despeito da extensiva dolomitização - pelo menos quatro gerações de cimento dolomitico foram observadas - os carbonatos ainda retêm as assinaturas isotópicas primárias de carbono. As variações de $\delta^{13} \mathrm{C}$ 


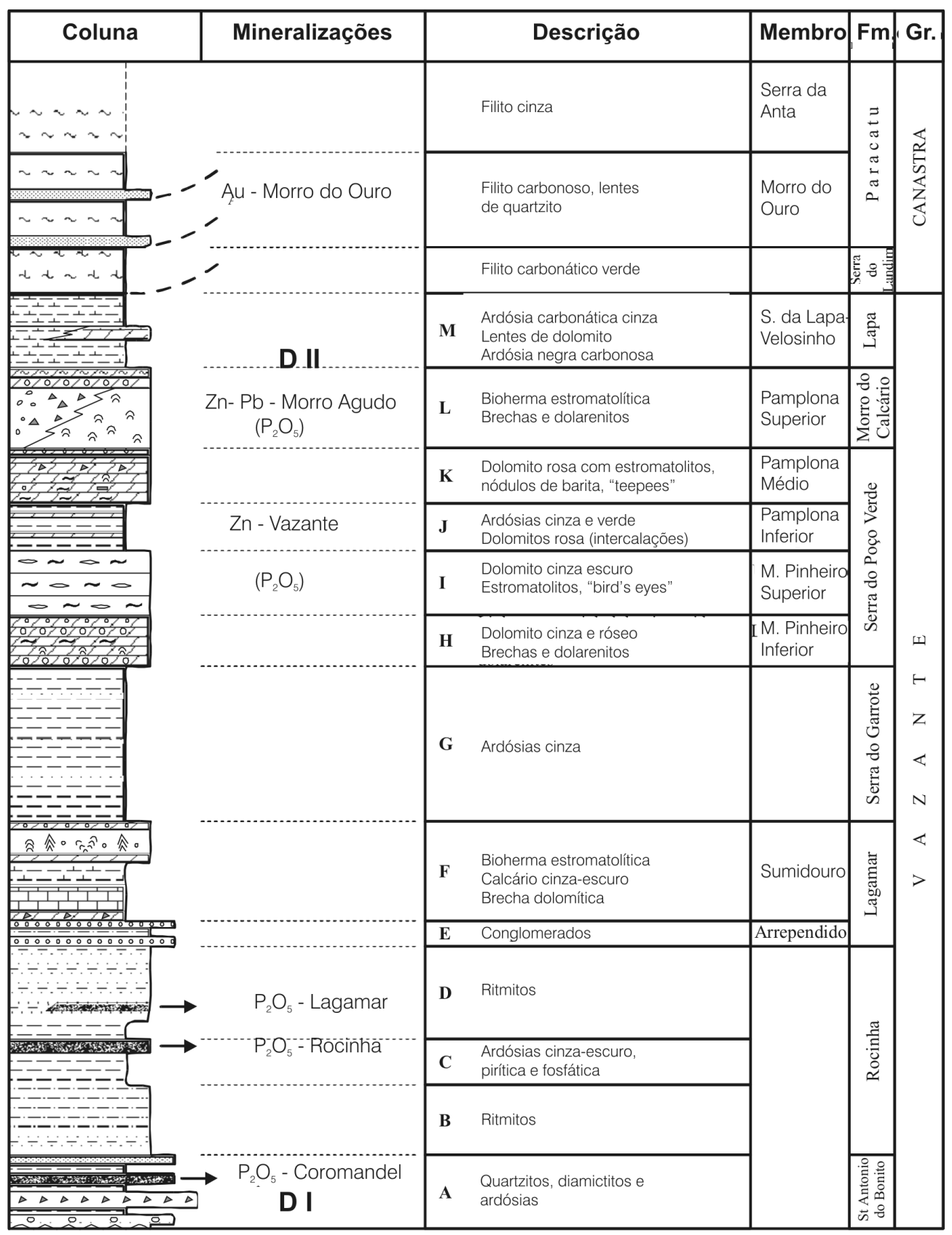

Figura 3 - Estratigrafia do Grupo Vazante segundo Dardenne (2001). D I e D II são horizontes glaciais (Azmy et al. 2005).

flutuam levemente em torno de $+2 \%$ VPDB na base da Formação Serra do Poço Verde, apresentando um pico negativo de - 4\%o no topo da mesma formação e outro de - 8\%o em carbonatos da Formação Lapa, logo acima do horizonte glácio-marinho (Fig. 4).

(2) Em contraste, somente poucas amostras apresentaram valores confiáveis de ${ }^{87} \mathrm{Sr} /{ }^{86} \mathrm{Sr}$, ou seja, que poderiam ter algum significado para indicar a composição da água do mar durante a sedimentação. Eles variam de 0,70614 a 0,70734 , sendo que os valores mais baixos correlacionam-se aos picos negativos de $\delta^{13} \mathrm{C}$. Os dados condizem com a possibilidade da sedimentação dos carbonatos desse intervalo estratigráfico ter ocorrido logo após eventos glaciais e durante o Sturtiano. A idade da Formação Lapa ainda é desconhecida, mas o valor menos radiogênico de ${ }^{87} \mathrm{Sr} r{ }^{86} \mathrm{Sr}(\sim 0,7068)$ e o pico negativo de $\delta^{13} \mathrm{C}$ foram também observados na Formação Rasthof, na Namíbia (Cráton do Congo), cuja idade radiométrica é bem definida em torno de 750 $\mathrm{Ma}$ (U-Pb em zircões, rocha vulcânica) (Hoffman et al. 1996).

(3) Os valores de $\delta^{34} \mathrm{~S}$ obtidos em sulfatos inclusos em carbonatos variam entre $+10,8$ e $+16,9 \%$ CDT, com um salto significativo para até $+21,3 \%$ na Formação Lapa.

Todas as assinaturas isotópicas obtidas coincidem com aquelas esperadas para a água do mar durante o Neoproterozóico.

Grupo Bambuí Os depósitos de plataforma carbo- 
(A)

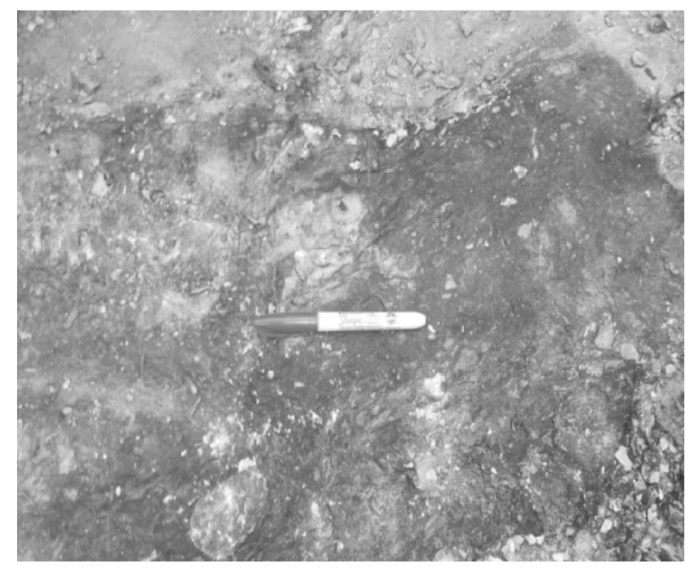

(B)

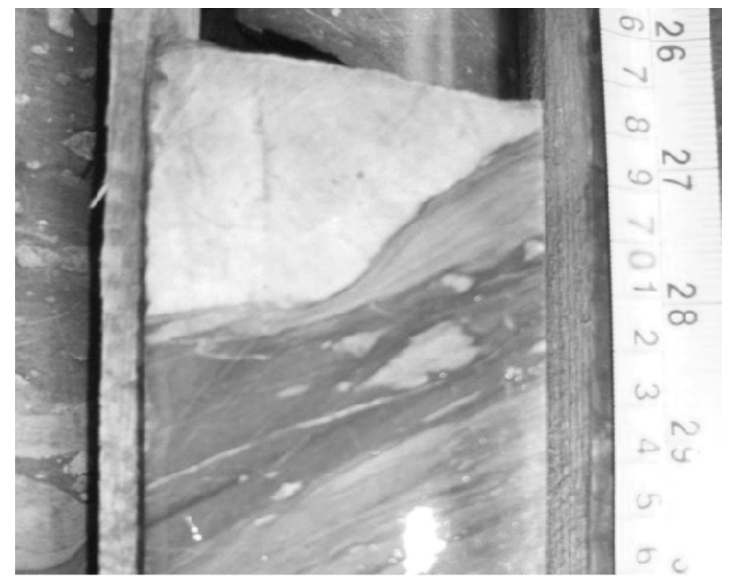

Figura 4 - Fotos a partir de afloramento (A) e testemunho de sondagem (B): (A) diamictito inferior (Formação Santo Antônio do Bonito) (DI) e (B) diamictito superior (DII) (Azmy et al. 2005).

nática do Grupo Bambuí estendem-se por mais de 200 mil quilômetros quadrados, abrangendo parcialmente os territórios de Minas Gerais, Goiás e Bahia. A figura 5 mostra uma seção típica do Grupo Bambuí na Bacia do São Francisco.

A espessura é variável e é provavelmente controlada por um sistema de falhas do embasamento (Misi et al. 2007). De acordo com levantamentos sísmicos regionais realizados pela Petrobrás, a área central da bacia pode atingir $1000 \mathrm{~m}$. Na área de Sete Lagoas, próximo a Belo Horizonte, foi estimada espessura de $600 \mathrm{~m}$ por Pedrosa-Soares et al. (1994) e na Serra do Ramalho, na borda leste da Bacia do São Francisco, furo de sondagem, realizado pela Companhia Baiana de Pesquisa Mineral (CBPM) atravessando toda a sucessão carbonática, alcançou $400 \mathrm{~m}$.

As unidades estratigráficas formaram-se durante dois ciclos tectono-sedimentares, de acordo com Misi et al. (2007) e Misi (2001):

CICLO 1 Sucessão marinha do tipo shallowingupward, iniciando com camadas pouco espessas e descontínuas de dolomitos róseos, argilosos, na base da Formação Sete Lagoas. Logo acima, ritmitos compostos por calcários laminados, com finas intercalações de argila e de silte, sugerindo uma transgressão marinha e águas relativamente profundas. No final do ciclo, constituindo o topo da Formação Sete Lagoas, ocorrem fácies típicas de sedimentação muito rasa: dolomitos com estruturas oolíticas, brechas intraformacionais e estruturas de ressecamento (teepees), revelando uma superfície erosiva de âmbito regional.

CICLO 2 Deposição de folhelhos e margas da Formação Serra de Santa Helena, revelando o início de uma nova transgressão marinha. A sedimentação tende a ficar cada vez mais rasa no sentido do topo, com o aparecimento de calcários oolíticos e pisolíticos da Formação Lagoa do Jacaré.

Estudos de quimioestratigrafia em carbonatos de diferentes áreas da Bacia do São Francisco (Torqua-

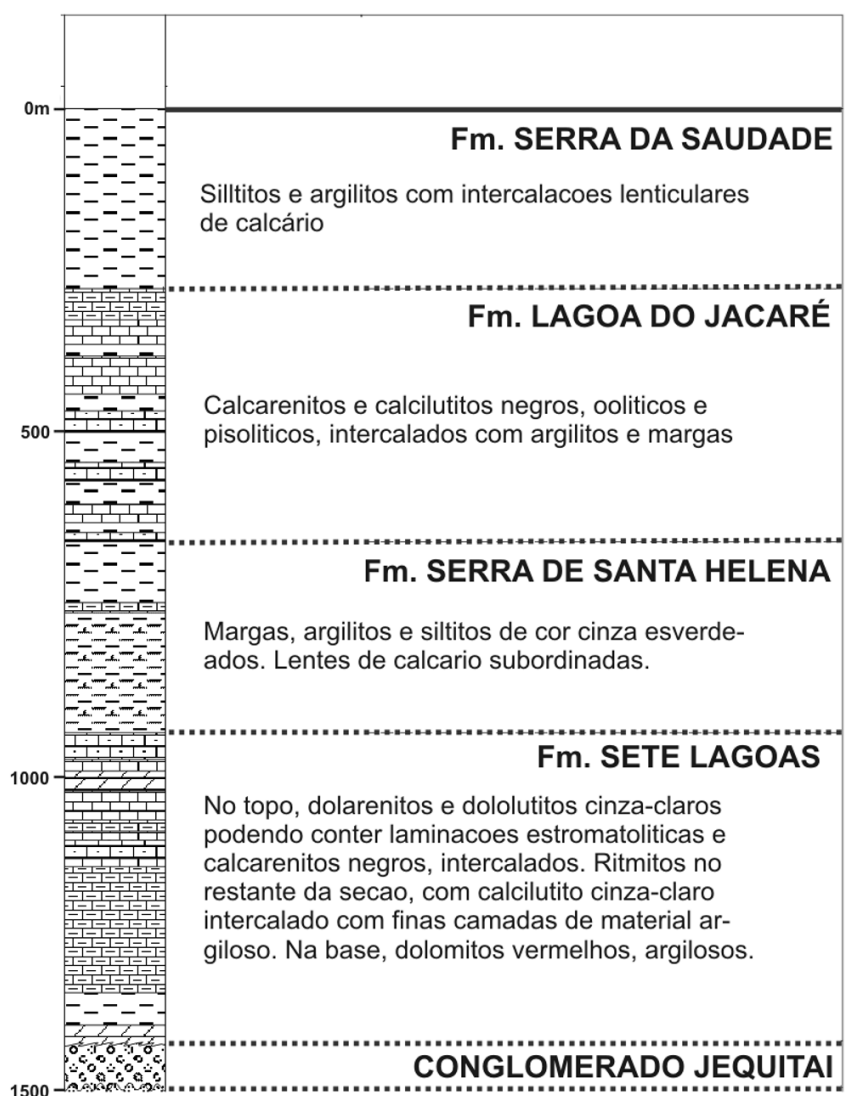

Figura 5 - Seção estratigráfica típica do Grupo Bambui com os nomes das formações que foram propostos por Branco \& Costa (1961).

to 1980, Kawashita 1998, Iyer et al. 1995, Kiang 1997, Santos et al. 2000, Powis 2006, Misi et al. 2007) mostram que:

1. A partir da base da seqüência carbonática do Grupo Bambuí, a composição de $\delta^{13} \mathrm{C}$ aumenta progressivamente no sentido do topo. $\mathrm{Na}$ base da Formação Sete Lagoas passa de valores baixos, em torno de $-4 \%$ VPDB até $+16 \%$ no topo da Formação Lagoa do Ja- 
caré. Por outro lado, os valores de $\delta^{18} \mathrm{O}$ das mesmas amostras são mais espalhados, não exibindo qualquer tendência.

2. Os calcários que se apresentam mais bem preservados $(\mathrm{Mn} / \mathrm{Sr} \leq 0,02$ e $\mathrm{Sr}$ total $>300 \mathrm{ppm})$ mostram valores de ${ }^{87} \mathrm{Sr} /{ }^{86} \mathrm{Sr}$ entre 0,707436 e 0,707507 .

Grupo Una O Grupo Una é composto por um pacote carbonático e pelitico com menos de $1000 \mathrm{~m}$ de espessura, contendo unidades siliciclásticas descontínuas e pouco espessas $( \pm 70 \mathrm{~m})$ de meta-arcósio na base (Formação Salitre). Essas unidades depositam-se sobre diamictitos glaciais (Formação Bebedouro) ou sobre quartzitos e pelitos mesoproterozóicos do Grupo Chapada Diamantina, que formam o embasamento local da Bacia de Irecê.

A seqüência carbonática da Formação Salitre é formada, da base para o topo, por sucessões de dolomitos argilosos, vermelhos (Unidade C), superpostos pos ritmitos constituídos de calcário cinza-claro intercalado com finas laminações de argila (Unidade B). Esses passam para fácies mais rasa, típica de planície de marés ("Unidade B1"), formadas por dolomitos oolíticos, com estruturas de marcas de onda e estratificações cruzadas por corrente e com estromatólitos colunares e laminares, passando acima para dolomitos com gretas de ressecamento (teepees) e estruturas nodulares de quartzo e de sulfetos, pseudomorfos de sulfato (gipsita). As unidades acima são formadas por margas, calcários argilosos e siltitos (Unidade A), iniciando um novo ciclo transgressivo. Acima, fácies mais rasa com calcário negro oolítico e pisolítico e com estruturas de marcas de onda e estratos cruzados por corrente ("Unidade A1") (Misi \& Souto 1975) (Fig. 6).

Torquato \& Misi (1977) e Misi \& Veizer (1998) realizaram estudos quimioestratigráficos em amostras bem preservadas e obtidas em seções estratigráficas bem controladas. As amostras da "Unidade A1" mostram um estreito intervalo de variação, com valores fortemente positivos de $\delta^{13} \mathrm{C}$ variando de $+8,0$ a $+9,4$ $\%$ VPDB e um intervalo também limitado de valores de $\delta^{18} \mathrm{O}$, de $-5,2$ a $-6,4 \%$ VPDB. Os valores da razão ${ }^{87} \mathrm{Sr} /{ }^{86} \mathrm{Sr}$ dessas mesmas amostras variam de 0,70745 a 0,70769 . Amostras da "Unidade B1" indicaram intervalo de $-0,6$ a $+1,1 \%$ e $\delta^{18} \mathrm{O}$ de $-6,2$ a $-7,5 \%$ VPDB, enquanto ${ }^{87} \mathrm{Sr} /{ }^{86} \mathrm{Sr}$ variou de 0,70753 a 0,70789 . Duas

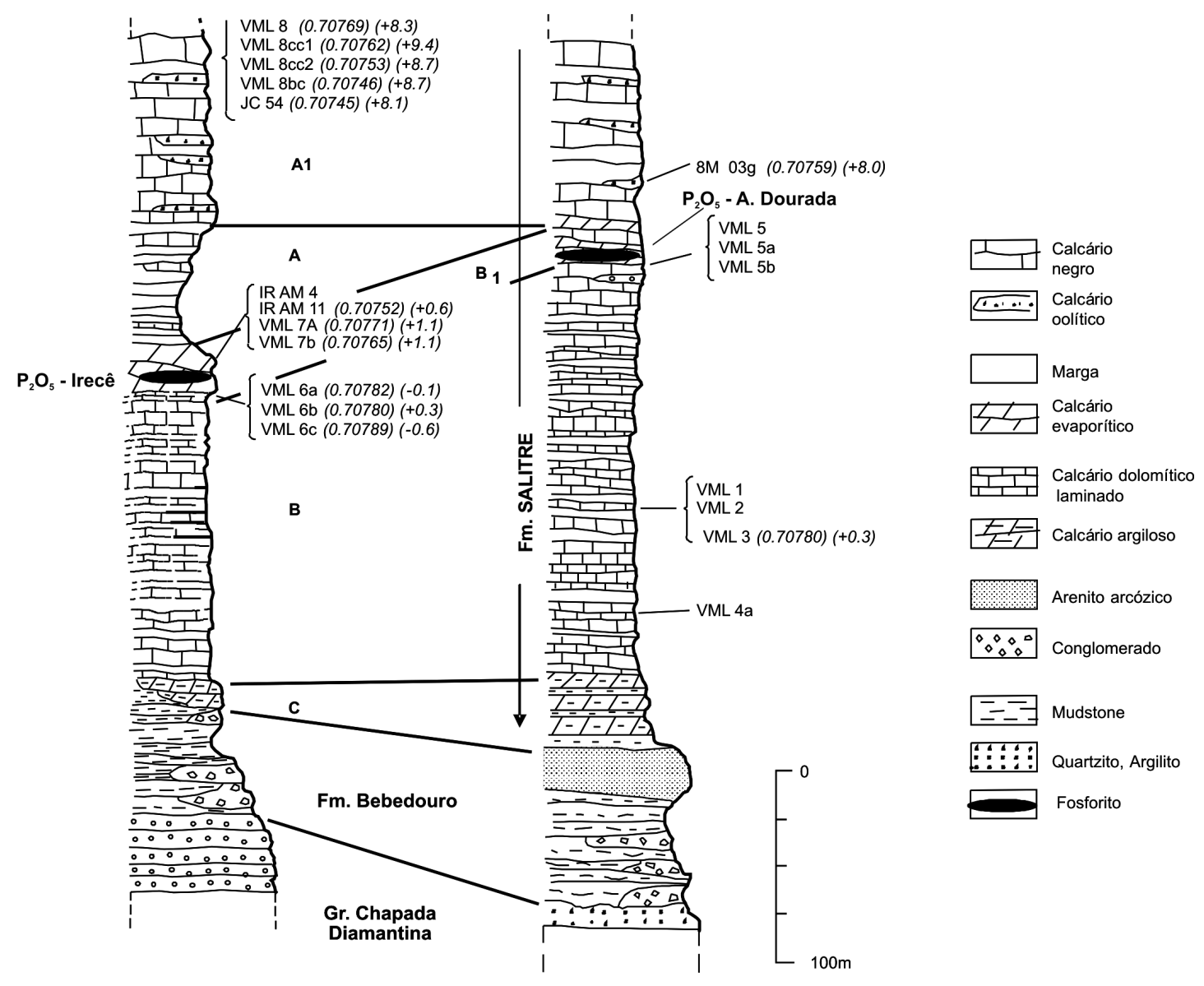

Figura 6 - Perfis estratigráficos do Grupo Una na Bacia de Irecê. Locais de amostragem indicados diretamente nas seções. Os dados de ${ }^{87} \mathrm{Sr}{ }^{86} \mathrm{Sr}$ e $\delta{ }^{13} \mathrm{C}$ são indicados entre parênteses. Todos os resultados são provenientes de amostras bem preservadas (alto Sr total e baixa relação Mn/Sr). Modificado a partir de Misi \& Veizer (1998). 
amostras da "Unidade B" mostraram valores de $\delta \delta^{13} \mathrm{C}$ de $+0,3$ e - 1,5 , e $\delta^{18} \mathrm{O}$ de $-6,2 \%$ VPDB. As razões ${ }^{87} \mathrm{Sr} /{ }^{86} \mathrm{Sr}$ foram de 0,70780 e 0,70847 . Na "Unidade C", obtiveram-se picos negativos de até $-5,1 \%$, comparáveis com valores obtidos em dolomitos de capa (cap dolomites) depositados sobre diamictitos neoproterozóicos em vários continentes.

DEPÓSITOS DE FOSFATO Os depósitos de fosfato são controlados estratigraficamente e distribuídos em todas as bacias (Figs. 1 e 7). Os depósitos de Coromandel, Rocinha e Lagamar, no Grupo Vazante, estão localizados sobre diamictitos glaciais (Formação Santo Antônio do Bonito: Dardenne 2001), na base do Ciclo 1. Mais acima, na Formação Morro do Calcário, em Morro Agudo, e na Formação Serra do Poço Verde (Membro Morro do Pinheiro Superior) ocorrem pequenas concentrações de colofanita constituindo parcialmente a matriz de brechas intraformacionais. Campos Belos, Nova Roma e Monte Alegre, no Grupo Bambuí, estão localizados imediatamente acima da Formação Jequitaí (diamictitos glaciais), na plataforma carbonática da Bacia do São Francisco, também na base do Ciclo 1. Cabeceiras e Cedro do Abaeté estão localizados no limite entre as Formações Lagoa do Jacaré e Serra da Saudade (Dardenne et al. 1986), no topo do Ciclo 2. Os fosforitos de Irecê, no Grupo Una, ocorrem em fácies dolomítica da "Unidade B1", equivalentes às de topo da Formação Sete Lagoas, Grupo Bambuí (final do Ciclo 1) (Misi \& Kyle 1994, Sanches 1998). Dentre esses depósitos, somente Lagamar, Rocinha e Irecê estão em produção.

Segue uma breve descrição dos depósitos de Rocinha e Lagamar (Grupo Vazante) e do depósito de Irecê (Grupo Una), os quais foram até agora estudados quanto às suas características geoquímicas (principal- mente isotópicas). Dados e informações mais detalhados sobre esses depósitos e sobre os outros podem ser vistos nos trabalhos de Dardenne et al. (1986), Misi (1992), Misi \& Kyle (1994), Da Rocha Araújo et al.(1992) e Sanches (1998).

Os depósitos de Coromandel, Rocinha e Lagamar estão localizados na porção basal do Grupo Vazante, na Formação Rocinha (Dardenne 2001). Essa unidade estratigráfica é formada por folhelhos negros, ricos em matéria orgânica, com laminações rítmicas de siltito e carbonato e depositadas sobre os diamictitos da Formação Serra do Bonito. As concentrações de fosfato formam grandes e pequenas lentes, laminações e agregados cristalinos finamente granulados de carbonato-fluorapatita. (Figs. $8 \mathrm{~A} \mathrm{e} \mathrm{B}$ ). Ocorre ainda fosforito intraclástico, especialmente no depósito de Lagamar (Dardenne et al. 1986). De acordo com esses autores, a fosfogênese dos depósitos de Rocinha e Lagamar foi um evento eodiagenético, caracterizado por processos de substituição de sedimentos carbonáticos e argilosos ricos em matéria orgânica.

Os fosfatos de Irecê, no Grupo Una, estão inteiramente concentrados em estruturas estromatolíticas (Fig. $8 \mathrm{C}$ ), e próximos a pequenos depósitos de sulfetos de $\mathrm{Fe}-\mathrm{Zn}-\mathrm{Pb}$, pertencentes à "Unidade $\mathrm{B} 1$ ". As concentrações de sulfetos estão na parte mais superior dessa Unidade, onde ocorrem indícios de exposição subaérea dos sedimentos (teepees, nódulos de quartzo e de sulfetos peseudomorfos de sulfatos e agregados radiais de pirita, pseudomorfos de gipsita). As concentrações primárias de fosfato, formadas por agregados de carbonato-fluorapatita finamente granulados, encontram-se imediatamente abaixo da zona dos sulfetos, diretamente associadas com estruturas estromatolíticas colunares e laminares. Os dolomitos encaixantes mostram estruturas de marcas de onda e estratos cruzados por corren-

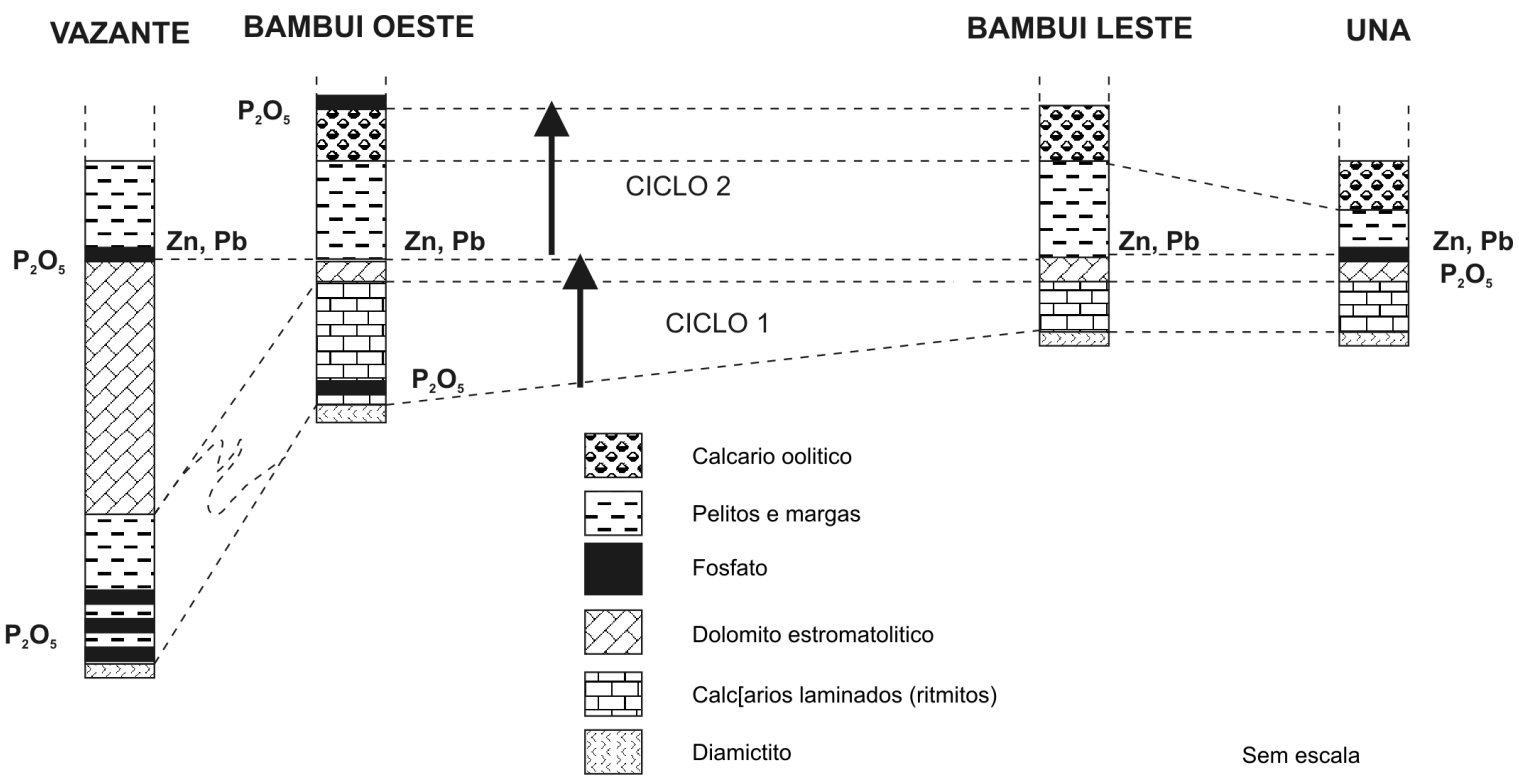

Figura 7 - Sucessões carbonáticas neoproterozóicas do Cráton do São Francisco com a localização dos depósitos de fosfato. 
(A)

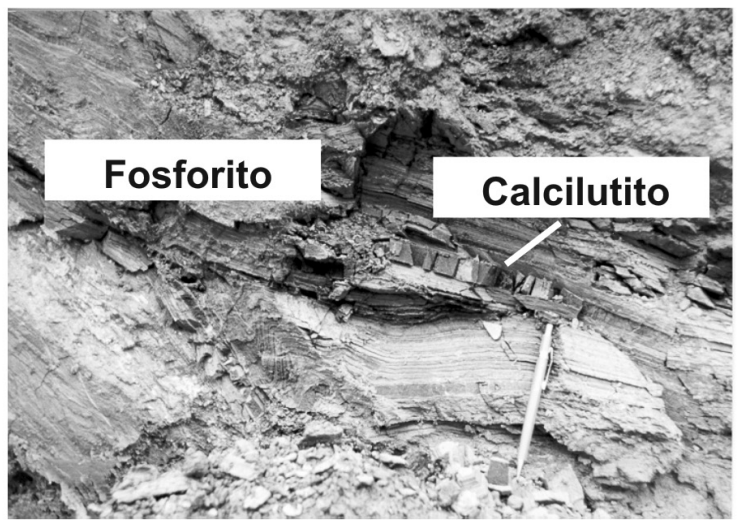

(C)

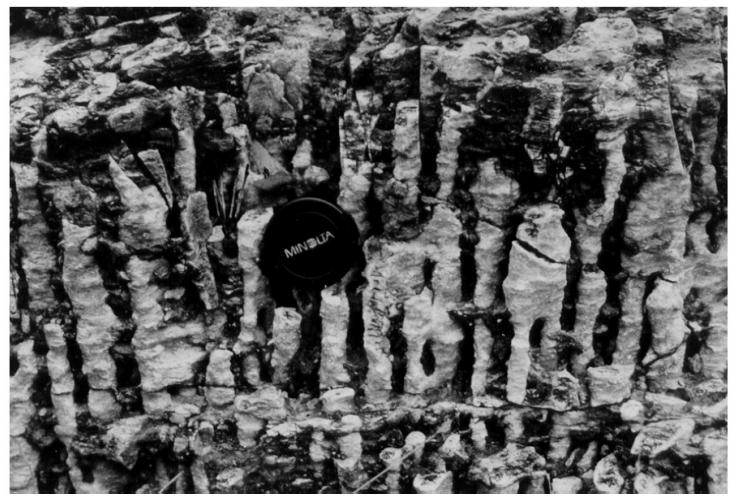

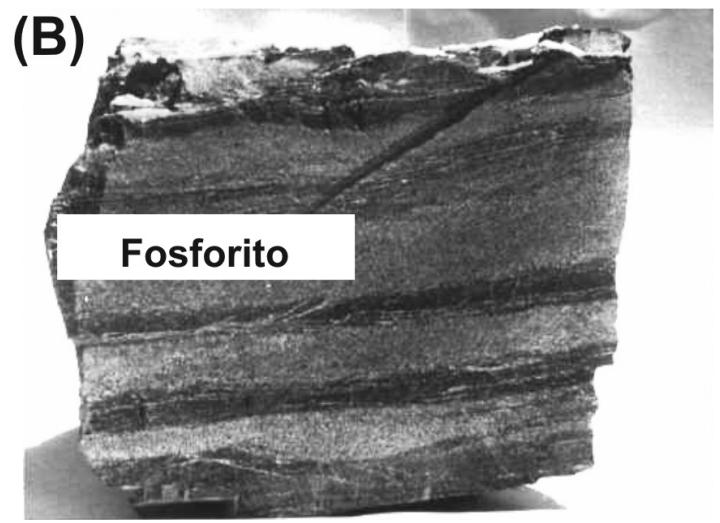

(D)

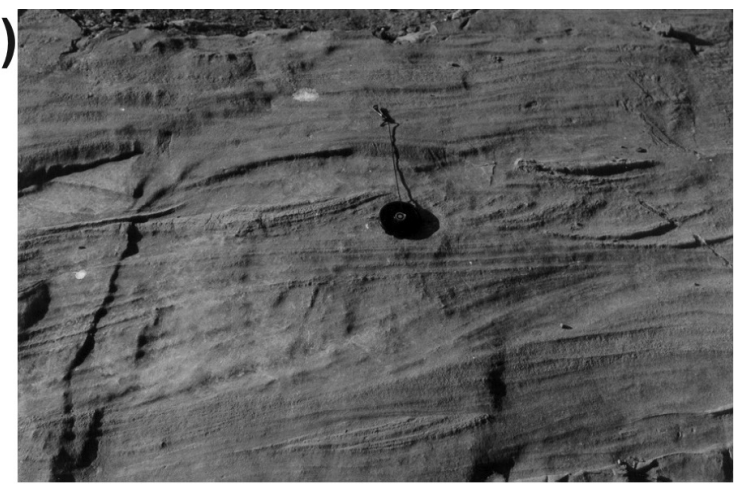

Figura 8 - (A) Fosforito de Rocinha com lente de calcilutito cinza, Formação Rocinha (Grupo Vazante). (B) Fosforito de Lagamar, Formação Rocinha (Grupo Vazante). (C) Fosforito de Irecê, estromatolitos colunares (Jurussania krilov, Srivastava 1982), ricos em fosfato (D) Estratos cruzados nos dolarenitos encaixantes do fosforito de Irecê, Unidade B1, Formação Salitre (Grupo Una).

tes, indicando a presença de um ambiente subaquático, porém muito raso, equivalente a zonas de inter-marés (Fig. 8 D). Misi \& Kyle (1994) descreveram três tipos de fosforito primário: estromatolítico colunar, estromatolítico laminar e intraclástico. A presença de clastos fosfáticos ressedimentados (Fig. 9 A), e de cimento dolomítico precoce nas bordas dos clastos de fosforito (Fig. 9 B) sugerem que a formação dos fosforitos estromatolíticos ocorreu em um processo diagenético precoce (Misi \& Kyle 1994).

MÉTODOS ANALÍTICOS Amostras de carbonatofluorapatita foram analisadas parcialmente na Universidade de Ottawa (Canadá), seguindo procedimentos descritos por Misi \& Kyle (1994), e na Universidade de Maryland (EUA). A preparação das amostras foi realizada no laboratório do Grupo de Metalogênese da Universidade Federal da Bahia.

Os agregados cristalinos do mineral foram separados com lupa binocular, lavados com água tridestilada, e, em seguida, tratados com solução de Silverman (Silverman et al. 1952, Kolodny \& Kaplan 1970) com o objetivo de eliminar impurezas de cimento carbonático. As amostras ficaram imersas na solução entre 24 e 72 horas $(50 \mathrm{~mL}$ de solução para cerca de $0,1 \mathrm{~g}$ de amostra), e sob agitação durante as primeiras 2 horas. Após esses procedimentos foram analisadas em difratô- metro de raios- $\mathrm{X}$, e somente aquelas isentas de cimento carbonático foram utilizadas para análises isotópicas de $\delta^{13} \mathrm{C}, \delta^{18} \mathrm{O}$ e ${ }^{87} \mathrm{Sr}{ }^{86} \mathrm{Sr}$ a partir do $\mathrm{CO}_{2}$ estruturalmente associado à fluorapatita. As amostras que continham impurezas foram novamente tratadas com solução de Silverman.

Com base na suposta abundância de 1-2\% em peso de carbono na estrutura do carbonato fluoropatita, 500 microgramas da amostra pulverizada e pré-tratada (isenta de carbonato não estrutural) foram colocados em um recipiente de estanho, que foi selado e em seguida submetido à combustão em um analisador elementar Eurovector. $\mathrm{O} \mathrm{CO}_{2}$ resultante foi transferido por meio de um "trap" de água e de uma coluna de cromatografia de gás para um espectrômetro de massas com fonte de gás Isoprime sob corrente de hélio, onde o $\mathrm{CO}_{2}$ foi quantificado e a composição do carbono isotópico foi determinada. A precisão da análise baseada nas medidas de padrões múltiplos (uréia) durante o curso da corrida da amostra foi melhor que 0,2 por mil.

Para a análise do isótopo de estrôncio, $5 \mathrm{mg}$ da amostra pulverizada foram dissolvidas em $\mathrm{HCl} 3 \mathrm{~N}$. Em seguida ela foi centrifugada para remover os sólidos, e o sobrenadante foi secado em frascos de Teflon. A amostra foi redissolvida em $\mathrm{HNO}_{3} 3 \mathrm{~N}$ e a solução resultante, juntamente com alíquotas de $\mathrm{HNO}_{3}$ concentrado e diluído, foram passadas através de uma pequena coluna 
(A)

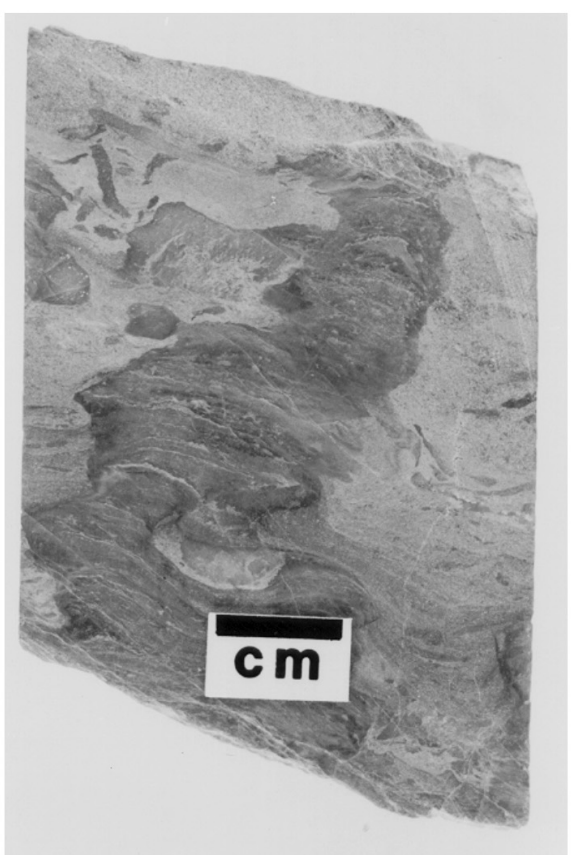

(B)

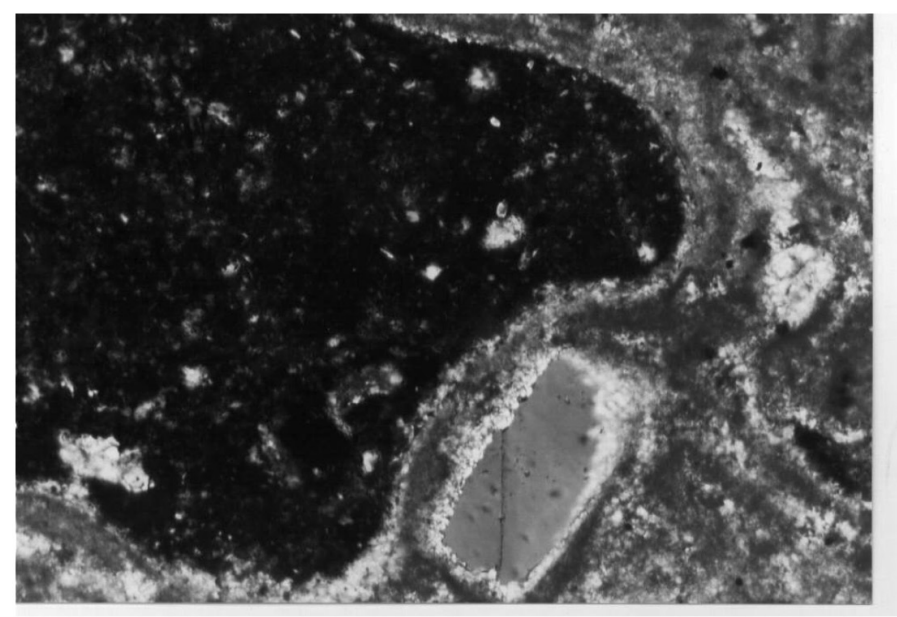

Figura 9 - (A) Estromatólito colunar rico em fosfato e intraclastos fosfáticos derivados de destruição das estruturas por ação de correntes, Irecê. (B) Desenvolvimento de cristais de dolomita em torno de clastos de fosforito (cor negra), Irecê.

de resina de Sr spec de modo a separar o estrôncio do cálcio, e de outros elementos. As soluções de estrôncio purificadas foram secadas e acumuladas sobre filamentos de rênio precalcinados com óxido de tântalo para melhorar a ionização. As amostras foram colocadas no carrossel de um espectrômetro de massa VG Sector 54 com ionização térmica para análise isotópica. Análises múltiplas do padrão de estrôncio NBS 987 durante as medidas apresentaram valores de 0,710242 $\pm 0,000008$.

RESULTADOS OBTIDOS Nos depósitos de Irecê, os valores de $\delta^{13} \mathrm{C}$ do carbonato fluorapatita variam de $-0,19$ a - 12,25\% VPDB. Os carbonatos eodiagenéticos associados mostram valores predominantemente positivos, variando de -0,25 a +9,51 (Misi \& Kyle 1994). O carbonato-fluoarapatita de Rocinha e Lagamar mostra variações de $\delta^{13} \mathrm{C}$ entre $-1,03$ e $-9,61 \%$ VPDB, enquanto carbonatos associados apresentam valores entre $-2,90$ e $+2,0$.

As razões ${ }^{87} \mathrm{Sr} /{ }^{86} \mathrm{Sr}$ são muito altas nos fosforitos de Irecê $(0,71070$ a 0,71587$)$. Porém, amostras de calcário muito fino, rico em matéria orgânica (micrita) e bem preservado ( $\mathrm{Sr}>800 \mathrm{ppm}$ e $\mathrm{Mn} / \mathrm{Sr}<0,01)$, provenientes do mesmo intervalo, forneceram valores variando entre 0,70765 e 0,70789 (Misi \& Veizer 1998). Em Rocinha e Lagamar, as razões ${ }^{87} \mathrm{Sr} /{ }^{86} \mathrm{Sr}$ do carbonatofluorapatita variam de 0,70760 a 0,70791 . Calcários micríticos intercalados (Fig. 8A) mostram variações de 0,70760 a 0,70886 . Todas as amostras desse intervalo da Formação Rocinha mostram-se muito bem preservadas, com $\mathrm{Sr}$ total acima de $1700 \mathrm{ppm}$ e $\mathrm{Mn} / \mathrm{Sr}$ muito baixo $(0,009$ a 0,56$)$.

A tabela 1 mostra os dados de composição isotópica dos depósitos estudados neste trabalho, bem como outros dados analíticos provenientes de estudos anteriores.

DISCUSSÃO E CONCLUSÕES Fosforitos neoproterozóicos estão presentes em diversos continentes, revelando a existência de um amplo episódio de formação de concentrações de fosfatos marinhos entre o final do Proterozóico e o início do Paleozóico, conforme demonstrado por Cook \& Shergold (1986). Esses autores sugeriram que os principais eventos de fosfogênese sucederam períodos glaciais, uma vez que as glaciações podem produzir uma grande quantidade de água fria, rica em nutrientes, o que resulta em aumento da produtividade orgânica na zona fótica, após o período glacial. Os depósitos de fosfato das bacias neoproterozóicas do Cráton do São Francisco são caracterizados pela sua íntima associação com estruturas estromatolíticas, o que pode ser uma importante indicação da influência de microorganismos controlando a fosfogênese nessas bacias. Além disso, alguns desses depósitos estão inequivocamente sobre diamictitos glaciais, outros nem tanto, embora a presença de valores negativos de $\delta^{13} \mathrm{C}$ nos horizonte carbonáticos logo abaixo dos depósitos possa sugerir que algum evento glacial discreto possa ter ocorrido antes da formação dos fosforitos.

Os dados isotópicos de $\mathrm{C}$ e $\mathrm{O}$ obtidos nos carbonatos encaixantes do fosforito de Irecê e no carbonato fluorapatita por Misi \& Kyle (1994), e os dados de $\mathrm{S}$ em sulfatos e sulfetos obtidos por Kyle \& Misi (1997), sustentam a interpretação da presença de um ambiente anóxico, provavelmente devido à ação de microorganismos anaeróbicos provavelmente associados aos tapetes de cianobactérias que deram origem aos estromatólitos (Misi \& Kyle 1994). Foi verificado um 
Tabela 1 - Composição isotópica e de elementos-traço obtidas nos fosforitos e carbonatos associados, depósitos de Irecê, Lagamar e Rocinha.

\begin{tabular}{|c|c|c|c|c|c|}
\hline & & $\mathrm{d}^{18} \mathrm{O}$ & $\mathrm{d}^{13} \mathrm{C}$ & ${ }^{87} \mathrm{Sr} /{ }^{86} \mathrm{Sr}$ & Descrição \\
\hline \multirow{17}{*}{ 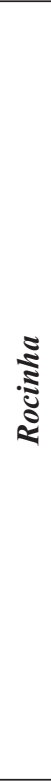 } & RO-AM-01 & $-10,3$ & 1 & 0,70769 & Lentes de calcário fino no fosforito \\
\hline & RO-AM-03 & $-10,3$ & $-0,4$ & 0,70786 & Lentes de calcário fino no fosforito \\
\hline & RO-AM-04 & $-9,9$ & $-2,9$ & 0,70769 & Lentes de calcário fino no fosforito \\
\hline & RO-AM-06 & $-9,9$ & $-1,4$ & 0,70772 & Lentes de calcário fino no fosforito \\
\hline & RO-F-70-70.6 & $-10,7$ & 2 & 0.70760 & Lentes de calcário fino no fosforito \\
\hline & RO-AM-09 & $-9,1$ & $-2,1$ & 0,70767 & Carbonato fluorapatita \\
\hline & RO-AM-12 & & & 0,70766 & Carbonato fluorapatita \\
\hline & LG 2 & & & 0,70791 & Carbonato fluorapatita \\
\hline & RO F-61-79 & & & 0,70869 & Lentes de calcário fino no fosforito \\
\hline & RO F-61-81 & & & 0,70886 & Lentes de calcário fino no fosforito \\
\hline & RO-AM-38 & & $-1,03$ & & Carbonato fluorapatita \\
\hline & RO-AM-24 & & $-2,99$ & & Carbonato fluorapatita \\
\hline & RO-AM-20A & & $-4,59$ & & Carbonato fluorapatita \\
\hline & RO-AM-20B & & $-3,71$ & & Carbonato fluorapatita \\
\hline & RO-AM-21 & & $-6,18$ & & Carbonato fluorapatita \\
\hline & RO-AM-22 & & $-5,18$ & & Carbonato fluorapatita \\
\hline & RO-AM-23 & & $-2,70$ & & Carbonato fluorapatita \\
\hline \multirow{6}{*}{ 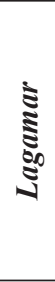 } & LG-AM-03A & & $-2,26$ & & Carbonato fluorapatita \\
\hline & LG-AM-03B & & $-9,61$ & & Carbonato fluorapatita \\
\hline & LG-AM-04 & & $-3,13$ & & Carbonato fluorapatita \\
\hline & LG-AM-05 & & $-4,16$ & & Carbonato fluorapatita \\
\hline & LG-AM-06 & & $-3,58$ & & Carbonato fluorapatita \\
\hline & LG-AM-07 & & $-4,11$ & & Carbonato fluorapatita \\
\hline \multirow{28}{*}{ 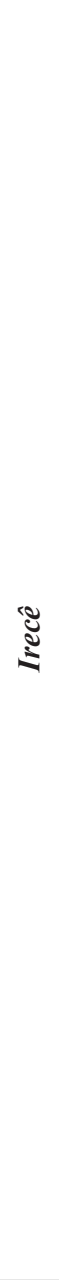 } & $25,65 \mathrm{~A}$ & $-6,2$ & $-5,28$ & & Carbonato Fluorapatita \\
\hline & $18,80 \mathrm{~A}$ & $-6,2$ & $-3,7$ & & Carbonato Fluorapatita \\
\hline & $18,80 \mathrm{C}$ & $-6,2$ & $-1,18$ & & Carbonato Fluorapatita \\
\hline & $10,92 \mathrm{C}$ & $-6,57$ & $-4,01$ & & Carbonato Fluorapatita \\
\hline & $19,16 \mathrm{Bc}$ & $-7,11$ & $-8,58$ & & Calcita no fosforito $(>25 \% \mathrm{P} 2 \mathrm{O} 5)$ \\
\hline & $25,65 \mathrm{Bc}$ & $-4,84$ & $-2,18$ & & Calcita no fosforito $(>25 \% \mathrm{P} 2 \mathrm{O} 5)$ \\
\hline & $18,80 \mathrm{Bc}$ & $-6,91$ & $-3,47$ & & Calcita no fosforito $(>25 \% \mathrm{P} 2 \mathrm{O} 5)$ \\
\hline & $10,92 \mathrm{Bc}$ & $-5,49$ & $-12,25$ & & Calcita no fosforito $(>25 \% \mathrm{P} 2 \mathrm{O} 5)$ \\
\hline & $10,92 \mathrm{D}$ & $-3,01$ & $-2,83$ & & Dolomita c/ carbonato fluorapatita \\
\hline & $19,16 \mathrm{Bd}$ & $-5,01$ & $-1,51$ & & Dolomita no fosforito (>25\% P2O5) \\
\hline & $25,65 \mathrm{Bd}$ & $-3,88$ & $-1,28$ & & Dolomita no fosforito (>25\% P2O5) \\
\hline & $10,92 \mathrm{Bd}$ & $-2,57$ & $-1,76$ & & Dolomita no fosforito $(>25 \%$ P2O5) \\
\hline & AM 8d & $-3,48$ & $-0,93$ & & Dolomita no fosforito $(>25 \%$ P2O5) \\
\hline & $43,42 \mathrm{~d}$ & $-1,55$ & 0,19 & & Dolomita no fosforito $(>25 \%$ P2O5) \\
\hline & IL 4019.16 & $-8,58$ & $-7,11$ & & Carbonato fluorapatita \\
\hline & IL 4113.92 & $-12,25$ & $-5,49$ & & Carbonato fluorapatita \\
\hline & IL 4825.65 & $-5,28$ & $-6,2$ & & Carbonato fluorapatita \\
\hline & IL 6318.80 & $-3,47$ & $-6,91$ & & Carbonato fluorapatita \\
\hline & IL-108(26,45) & 0,00 & $-7,18$ & 0,71263 & Carbonato fluorapatita \\
\hline & IL-39(7,94) & 0,00 & $-6,79$ & 0,71577 & Carbonato fluorapatita \\
\hline & IL-108(24,20) & 0,00 & $-8,18$ & 0,71587 & Carbonato fluorapatita \\
\hline & IL-39(8,36) & 0,00 & $-8,54$ & 0,71289 & Carbonato fluorapatita \\
\hline & IL-80 $(28,14)$ & 0,00 & $-4,95$ & 0,71260 & Carbonato fluorapatita \\
\hline & IL-77(21,95) & 0,00 & $-6,50$ & 0,71282 & Carbonato fluorapatita \\
\hline & IL-39(6,36) & 0,00 & $-7,35$ & 0,71070 & Carbonato fluorapatita \\
\hline & IL-77(20,28) & 0,00 & $-7,77$ & 0,71079 & Carbonato fluorapatita \\
\hline & IL-108(27,89) & 0,00 & $-4,94$ & 0,71290 & Carbonato fluorapatita \\
\hline & IL-103 $(8,13)$ & & & 0,71070 & Carbonato fluorapatita \\
\hline
\end{tabular}


importante empobrecimento de ${ }^{13} \mathrm{C}$ em relação ao esperado para cimentos marinhos, sugerindo a presença de um ambiente típico de redução de sulfatos em sedimentos orgânicos. Os isótopos de $\mathrm{S}$ dos sulfatos (barita e gipsita) assim como dos sulfetos (esfalerita, galena e pirita), por sua vez, apresentam valores consistentemente elevados de $\delta^{34} \mathrm{~S}$ : entre +25 e $+31 \%$ CDT para os sulfatos e de +19 a $+23 \%$ o CDT para os sulfetos, o que pode ser conseqüência de processos de redução termoquímica de uma fonte limitada de sulfatos, devido à presença de matéria orgânica (Kyle \& Misi 1997). Os novos dados de isótopos de carbono apresentados neste trabalho reforçam a hipótese acima (Fig. 10).

Independente do mecanismo de precipitação do carbonato fluorapatita - se autigênica ou por substituição de minerais carbonáticos durante a diagênese - o ambiente deposicional representado pelas encaixantes dos fosforitos dos Grupos Vazante e Una são condizentes com a formação de fosforitos. A degradação da matéria orgânica nas colônias de bactérias que teriam dado origem às estruturas estromatolíticas, poderia ter sido responsável pelo enriquecimento local em P das águas intersticiais.

A semelhança das litofácies e das mega-seqüências de um modo geral, bem como a ocorrência de

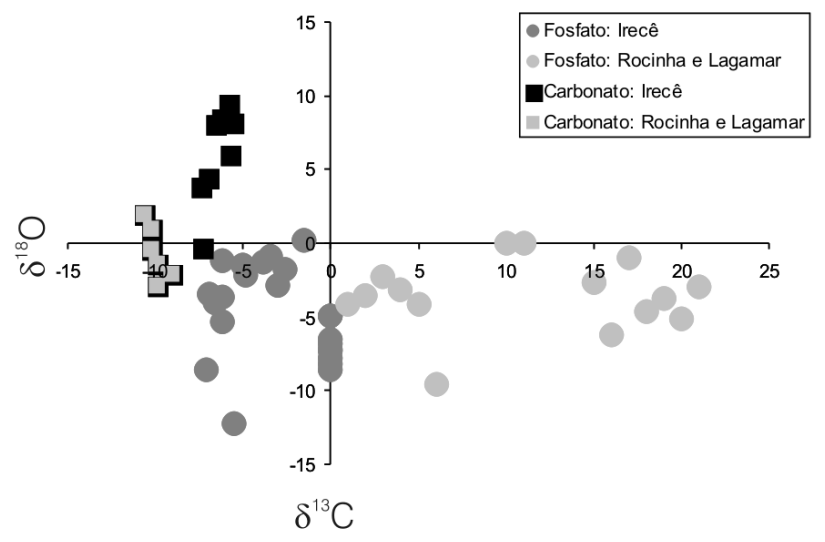

Figura 10 - Variações de $\delta^{13} C$ versus $\delta^{18} \mathrm{O}$ em fosfatos e carbonatos associados dos depósitos estudados. Não foram realizadas determinações de $\delta^{18} \mathrm{O}$ nos fosfatos de Rocinha e Lagamar.

depósitos de $\mathrm{Zn}-\mathrm{Pb}$ e de fosfato restritos a intervalos estratigráficos bem limitados nos Grupos Vazante, Bambuí e Una, sugerem a existência de correlações entre essas unidades estratigráficas (Fig. 11). Os menores valores de ${ }^{87} \mathrm{Sr} /{ }^{86} \mathrm{Sr}$ obtidos em cada uma dessas sucessões

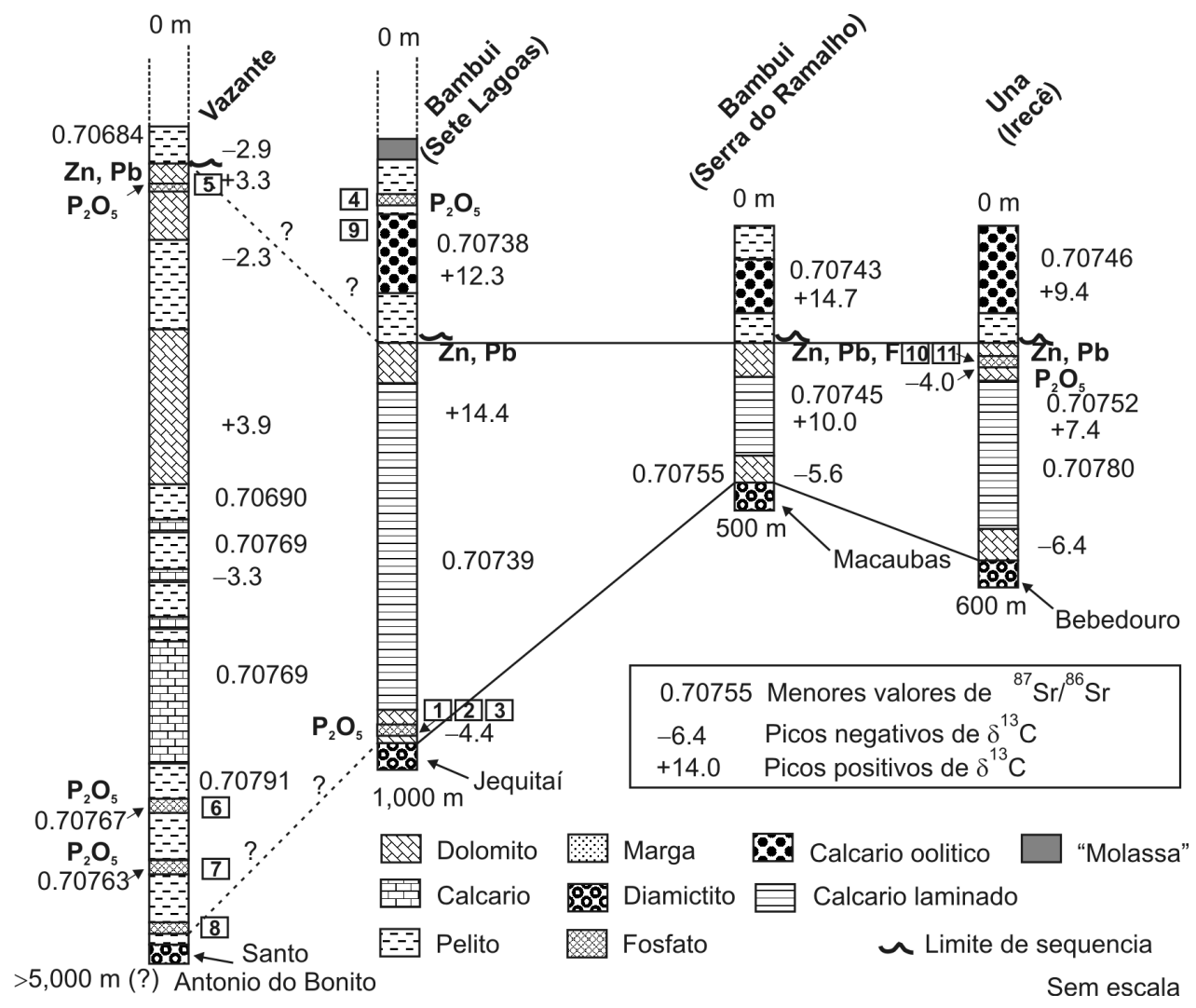

Figura 11 - Correlação entre as sucessões neoproterozóicas do Cráton do São Francisco e depósitos de fosfato. Depósitos indicados por números (1 a 11). Ver figura 1 para identificar os depósitos. Vazante: GrupoVazante; Bambui (Sete Lagoas): Grupo Bambuí, Oeste da Bacia do São Francisco; Bambuí (Serra do Ramalho): Grupo Bambuí, Leste da Bacia do São Francisco; Una (Irecê): Grupo Una, Bacia de Irecê. Modificado a partir de Misi et al. (2006). 
(variando de 0,70684 a 0,70791 ) sustentam as correlações sugeridas. Os dados isotópicos de $\mathrm{C}$ revelam, por sua vez, fortes picos negativos associados às litofácies pós-glaciais e/ou a eventos transgressivos. Os carbonatos dessas unidades são moderada ou fortemente enriquecidos em ${ }^{13} \mathrm{C}$, variando de $+3 \mathrm{a}+14 \%$. Amostras de afloramento da Formação Serra do Garrote, com alto conteúdo de $\mathrm{Sr}$ total, forneceram valores em torno de 0,70691, semelhante ao obtido em uma amostra coletada em furo de sondagem, em calcário da Formação Lapa $(\sim 0,7068)$, imediatamente acima da Formação Morro do Calcário, onde existem também ocorrências de carbonato fluorapatita. Esses valores mais baixos da razão ${ }^{87} \mathrm{Sr} /{ }^{86} \mathrm{Sr}$ sugerem a possibilidade de o Grupo Vazante ser mais antigo do que o Grupo Bambuí (cf. Jacobsen \& Kaufman 1999). Entretanto, os depósitos de carbonato fluorapatita de Rocinha e Lagamar, ambos localizados em unidades estratigráficas abaixo da Formação Serra do Garrote, fornecem valores consistentemente dentro da mesma faixa obtida nas outras seções dos Grupos Bambuí e Una (Tabela 1). As correlações quimioestratigráficas baseiam-se na análise de amostras bem preservadas, uma vez que somente aquelas que mostraram valores de $\mathrm{Mn} / \mathrm{Sr}$ abaixo de 0,2 e concentração de $\mathrm{Sr}$ total acima $300 \mathrm{ppm}$ foram consideradas para interpretação. As razões ${ }^{87} \mathrm{Sr} /{ }^{86} \mathrm{Sr}$ utilizadas para correlações foram sempre as de mais baixo valor, obtidas em cada seção. Com relação aos dados de isótopos de carbono, foram considerados para correlações todos aqueles provenientes de carbonatos de granulação fina (tanto calcário quanto dolomito). No entanto, estudos quimioestratigráficos adicionais e novas idades radiométricas são necessários, pelo menos com relação ao Grupo Vazante.

A formação de depósitos de fosfato nas bacias neoproterozóicas do Cráton do São Francisco tem grande significado econômico devido à importância do fósforo para a agricultura. Se corretas as correlações propostas e os processos fosfogenéticos envolvidos, novas perspectivas certamente se abrirão para exploração mineral nessas bacias.

\section{Referências}

Azmy K., Veizer J., Misi A., Oliveira T.F., Sanches A.L. \& Dardenne M.A. 2001. Dolomitization and isotope stratigraphy of the Vazante Formation, São Francisco Basin, Brazil. Precambrian Res., 112:303-329.

Azmy K., Kaufman A.J., Misi A., Kimura H. \& Oliveira T.F. 2005. Chemostratigraphy of Neoproterozoic sequences of the Vazante group, São Francisco basin, Brazil: new data and review. In: Simpósio sobre o Cráton do São Francisco, 3, Salvador, Bahia, Brazil, August 14-18, Short Papers, p. 269-273.

Branco J.J.R. \& Costa M.T. 1961. Roteiro da excursão Belo Horizonte - Brasília. In: Congresso Brasileiro de Geologia, 14, Brasília, 1960, Instituto de Pesquisas Radioativas, UFMG, Publicação 15, Belo Horizonte, 25 p.

Brody K.B., Kaufman A.J., Eigenbrode, J.L. \& Cody, G.D. 2004. Biomarker geochemistry of a post-glacial Neoproterozoic succession in Brazil. In: Geological Society of America, 2004 Denver Annual Meeting, November 7-10. Abstracts with Programs, p. 477.

Condie K.C. 2002. The supercontinent cycle: are there two patterns of ciclicity? J. African Earth Sci., 35: 179-183.

Cook P.J. \& Shergold J.H. 1986. Proterozoic and Cambrian phosphorite: nature and origin. In: P.J. Cook \& J.H. Shergold (eds.) Phosphate Deposits of the World. Proterozoic and Cambrian Phosphorites, Cambridge University Press, Cambridge, p. 369-386.

Dardenne M.A. 2000. The Brasilia Fold Belt. In: U.G. Cordani, E.J. Milani, A. Thomaz-Filho \& D.A. Campos (eds.) Tectonic Evolution of South América. 31st International Geological Congress, Rio de Janeiro, p. 231-263.

Dardenne M.A. 2001. Lithostratigraphic sedimentary sequences of the Vazante Group. In: A. Misi \& J.B.G. Teixeira (eds.) Proterozoic Base Metal Deposits of Africa and South America, IGCP 450 1st Field Workshop, Belo Horizonte and Paracatu, Brazil, p. 48-50.
Dardenne M.A., Trompette R., Magalhães L.F. \& Soares L.A. 1986. Proterozoic and Cambrian phosphorites - regional review: Brazil. In P.J. Cook \& J.H. Shergold (eds.) Phosphate Deposits of the World. Proterozoic and Cambrian Phosphorites, Cambridge University Press, Cambridge, p. 116-131.

Da Rocha Araujo P.R., Flicoteaux R., Paron C. \& Trompette R. 1992. Phosphorites of Rocinha mine-Patos de Minas (Minas Gerais, Brazil): genesis and evolution of a Middle Proterozoic deposit tectonized by the Brasiliano Orogeny. Econ. Geol., 87(2):332-351.

Iyer S.S., Babinski M., Krouse H.R. \& Chemale Jr. F. 1995. Highly $13 \mathrm{C}$ enriched carbonate and organic matter in the Neoproterozoic sediments of the Bambuí Group, Brazil. Precambrian Res., 73:271-282.

Hoffman P.F., Hawkins D.P., Isachsen S.E. \& Bowiring S.A. 1996. Precise U-Pb zircon ages for early Damaran magmatism in the Summas Mountains and Welwitschia inlier, northern Damara belt, Namibia. Geol. Sur. Namibia Comm., 11:47-52.

Jacobsen, S.B. \& Kaufman A.J. 1999. The Sr, C and O isotopic evolution of Neoproterozoic seawater. Chem. Geol., 161:37-57.

Kawashita K. 1998. Rochas carbonáticas neoproterozóicas da América do Sul: idades e inferências quimioestratigráficas. Tese de Livre Docência, Universidade de São Paulo, $126 \mathrm{p}$.

Kiang, C.H. 1997. Isótopos estáveis $(C, H, O) e^{87}{ }^{8}{ }^{86}{ }^{86}$ : Implicações na estratigrafia e na paleo-circulação de fluidos na Bacia do São Francisco. Tese de Livre Docente, UNESP, São Paulo, Brazil.

Kolodny, Y. \& Kaplan, I.R. 1970 Carbon and oxygen isotopes in apatite $\mathrm{CO}_{2}$ and coexisting calcite from sedimentary phosphorite. J. Sed. Petrol., 40:954-959.

Kyle J.R. \& Misi, A. 1997. Origin of Zn-Pb-Ag sulfide de- 
posits within Upper Proterozoic phosphate-rich carbonate strata, Irecê basin, Bahia, Brazil. Intern. Geol. Review, 39:383-399.

Martins M. 1999. Análise estratigráfica das seqüencias Mesoproterozóicas (borda oeste) e Neoproterozóicas da Bacia do São Francisco. Dissertação de Mestrado, Instituto de Geociências, Universidade Federal do Rio Grande do Sul.

Misi A. 1992. Geologia e gênese da fosforita de Irecê. Rev. Bras. Geoc., 22:399-406.

Misi A. 2001. Estratigrafia isotópica das seqüências do Supergrupo São Francisco, coberturas neoproterozóicas do Cráton do São Francisco. Idade e correlações. In: C.P. Pinto \& M.A. Martins-Neto (eds.) Bacia do São Francisco. Geologia e Recursos Naturais. SBG, Núcleo de Minas Gerais, p. 67-92.

Misi A. \& Souto P.G. 1975. Controle estratigráfico das mineralizações de $\mathrm{Pb}-\mathrm{Zn}-\mathrm{F}-\mathrm{Ba}$ do Grupo Bambuí, parte leste da Chapada de Irecê (Bahia). Rev. Bras. Geoc., 5:30-45.

Misi A. \& Kyle J.R. 1994. Upper Proterozoic carbonate stratigraphy, diagenesis, and stromatolitic phosphorite formation, Irecê basin, Bahia, Brazil. J. Sed. Res., 64:299310 .

Misi A. \& Veizer J. 1998. Neoproterozoic carbonate sequences of the Una Group, Irecê Basin, Brazil: Chemostratigraphy, age and correlations. Precambrian Res., 89:87100.

Misi A., Sanches A.L., Kaufman A.J., Veizer J., Azmy K., Powis K. \& Teixeira J.B.G. 2006. $\delta^{13} \mathrm{C}$ and ${ }^{87} \mathrm{Sr} /{ }^{86} \mathrm{Sr}$ of phosphorites from the São Francisco craton, Brazil: phosphogenesis and correlations. In: South American Symposium on Isotope Geology, 5, Punta del Este, Uruguay, April 21-24, Short Papers, p. 263-266.

Misi A., Kaufman A.J., Veizer J., Powis K., Azmy K., Boggianni P.C., Gaucher C., Teixeira J.B.G., Sanches A.L. \& Iyer S.S.S. 2007. Chemostratigraphic Correlation of Neoproterozoic Successions in South America. Chem. Geol., 237:161-185.

Olcott A.N., Sessions A.L., Corsetti F.A., Kaufman A.J. \& Oliviera T.F. de. 2005. Biomarker evidence for photo- synthesis during Neoproterozoic glaciation. Science, 310:471-474.

Pedrosa-Soares A.C., Dardenne M.A., Hasui Y., Castro F.D.C., Carvalho M.V.A. \& Reis A.C. 1994. Mapa Geológico do estado de Minas Gerais e Nota Explicativa, Secretaria de Recursos Minerais, Hídricos e Energéticos, Companhia Mineradora de Minas Gerais (COMIG), mapas e texto, $97 \mathrm{p}$.

Powis K. 2006. Stable Isotope Geochemistry of the Bambui Group at Serra do Ramalho, Bahia, Brazil. Doctoral Thesis, Department of Earth Science, University of Ottawa, $187 \mathrm{p}$.

Sanches A.L. 1998. Caracterização Cristalográfica e Química do Fosforito de Irecê. Dissertação de Mestrado, Instituto de Geociências, Universidade Federal da Bahia, $105 p$.

Santos R.V., Alvarenga C.J.S., Dardenne M.A., Sial A.N. \& Ferreira V.P. 2000. Carbon and oxygen isotope profiles across Meso-Neoproterozoic limestones from central Brazil: Bambuí and Paranoá Groups. Precambrian Res., 104:107-122.

Silverman S.R., Fuyat R.K. \& Weiser J.D. 1952. Quantitative determination of calcite associated with carbonatebearing apatites. Am. Mineral., 37:211-222.

Srivastava N.K. 1982. Algumas observações sobre estromatolitos dos Grupos Una (Bahia) e Vasa-Barris (Sergipe), Nordeste do Brasil. Ciências da Terra, 3:7-11.

Torquato J.R.F. \& Misi A. 1977. Medidas isotópicas de carbono e oxigênio em carbonatos do Grupo Bambuí na região centro-norte do estado da Bahia. Rev. Bras. Geoc., 7:14-24.

Torquato J.R.F. 1980. Aplicações do estudo de isótopos de carbono e oxigênio ao estudo do Precambriano brasileiro. Tese Professor Titular, Universidade Federal do Ceará, 268 p.

Manuscrito CSF-23

Submetido em 31 de maio de 2006 Aceito em 01 de março de 2007 